\title{
Memórias da violência em "Amuleto" de Roberto Bolaño
}

DOI: https://doi.org/10.22409/pragmatizes.v10i18.40211

\section{Norma Sueli de Araújo Menezes ${ }^{1}$ Júlia Morena Silva da Costa ${ }^{2}$}

\begin{abstract}
Resumo: Este ensaio objetiva apresentar uma análise da violência presente no livro "Amuleto" do escritor chileno Roberto Bolaño. O romance está contextualizado no início da década de 1970, momento de grandes tensões políticas e de significativa violência no México e do início da ditadura militar-empresarial chilena (1973-1990). Os regimes ditatoriais, embora em circunstâncias diferentes, foram (e são ainda) episódios marcantes que unem os países latino-americanos. Identificaremos as diversas formas de violência ocorridas na América Latina, especificamente, no Chile e no México durante o período mencionado, assim como, qual a relação entre a política e a literatura presentes na referida obra. Os atuais discursos políticos que circulam em nossa sociedade sinalizam que grande parte da população brasileira provavelmente ignora parte significativa da história, inclusive do Brasil, nas décadas de 1960/1970, ou seja, a memória produzida sobre este período não deu conta de fazer conhecer os horrores e as atrocidades cometidos durante os mais de 20 anos de governo militar no país. A partir da abordagem do lugar da poesia e dos poetas na década de 1970, a narradora de Amuleto versa sobre seu papel de defensora da poesia e da memória política do México e do Chile de meados do século XX, de forma indissociável. Com seu discurso circular, calcado na reiteração de eventos traumáticos que presenciou, em especial, à invasão à UNAM, o Massacre de Tlatelolco (1968) e o golpe militar chileno (1973). Neste último fato, relatado pelo personagem Arturo Belano, há um trabalho de escavação memorialística, tanto nas ocorrências históricas mencionadas, como dos intentos poéticos do distrito federal mexicano. Os jovens poetas narrados pela protagonista defendiam o livre trânsito entre vida e poesia, se opunham aos moldes acadêmicos vigentes encarnados na figura de Octavio Paz, como também do poder hegemônico. O movimento poético desses jovens latino-americanos da década de 1970 agrega as muitas inquietações dos seus integrantes. A paixão pela poesia é o princípio básico que dá unidade ao grupo que buscava em cada ato e em cada verso um novo modo de explicar o mundo através de uma poesia sem burocracias, sem espaços de poder e legitimações padronizadas. Este estudo contribui para a indispensabilidade de se manter vivos os horrores e traumas que aconteceram durante os regimes autoritários e as ditaduras militares na América Latina e suas reverberações, considerando, sobretudo, que a memória pode ser um potente instrumento utilizado na reconstrução da história. Serão utilizados textos teóricos e críticos de Paul Ricoeur (1996), Nascimento (2008), Seligmann-Silva (2003), Sarlo (2007) e Rojo (2012), Bolognese (2009), Villarreal (2011), entre outros.
\end{abstract}

Palavras-chave: literatura; violência; política; vanguarda; cânone.

\footnotetext{
${ }^{1}$ Norma Sueli de Araújo Menezes. Mestranda do Programa de Pós-Graduação Literatura e Cultura da Universidade Federal da Bahia. E-mail: norma_81@hotmail.com - https://orcid.org/0000-0001-73208935

2 Júlia Morena Silva da Costa. Doutora em Literatura e Cultura (UFBA), professora do Instituto de Letras da Universidade Federal da Bahia/UFBA, Brasil. E-mail: juliamorenacosta@gmail.com https://orcid.org/0000-0002-2272-9893
}

Texto recebido em 23/12/2019 e aceito para publicação em 21/01/2020. 


\section{Memorias de la violencia en "Amuleto" de Roberto Bolaño}

Resumen: Este ensayo tiene como objetivo presentar un análisis de la violencia existente en el libro "Amuleto" del escritor chileno Roberto Bolaño. La novela se contextualiza a principios de la década de 1970, una época de gran tensión política y violencia significativa en México y el comienzo de la dictadura militar-comercial chilena (1973-1190). Los regímenes dictatoriales, aunque bajo diferentes circunstancias, fueron (y siguen siendo) episodios notables que unen a los países latinoamericanos. Identificaremos las diversas formas de violencia que ocurrieron en el continente latino-americano, específicamente, Chile y México durante el período mencionado, así como cuál es la relación entre política y literatura presente en ese trabajo. Los discursos políticos actuales que circulan en nuestra sociedad indican que una gran parte de la población brasileña probablemente ignora una parte importante de la historia reciente de América Latina, incluido Brasil, en las décadas de 1960/1970 para dar a conocer los horrores y atrocidades cometidos durante los más de 20 años de gobierno militar en el país. Desde el enfoque del lugar de la poesía y los poetas en la década de 1970, la narradora de Amuleto aborda su papel de defensora de la poesía y la memoria política de México y Chile de mediados del siglo XX, inseparablemente. Con su discurso circular, basado en la reiteración de eventos traumáticos que presenció, en particular, la invasión de UNAM, la Masacre de Tlatelolco (1968) y el golpe militar chileno (1973). Este último hecho vivido por el personaje Arturo Belano, hay un trabajo de excavación memorialista de las ocurrencias históricas mencionadas, y de las intenciones poéticas del distrito federal mexicano. Los jóvenes poetas narrados por la protagonista defendían el libre tránsito entre la vida y la poesía, y hacían oposición a los moldes académicos actuales encarnados en la figura de Octavio Paz, así como al poder hegemónico. El movimiento poético de estos jóvenes latinoamericanos de la década de 1970 se suma a las muchas preocupaciones de sus miembros. La pasión por la poesía es el principio básico que da unidad al grupo que buscaba en cada acto y verso una nueva forma de explicar el mundo a través de la poesía sin burocracias, sin espacios de poder y legitimaciones estandarizadas. Este estudio contribuye a la indispensabilidad de mantener vivos los horrores y traumas que ocurrieron durante los regímenes autoritarios y las dictaduras militares en América Latina y sus reverberaciones. Sobre todo, porque entiende que la memoria puede ser un poderoso instrumento utilizado en la reconstrucción de la historia. Serán utilizados textos teóricos y críticos de Paul Ricoeur (1996), Nascimento (2008), Seligmann-Silva (2003), Sarlo (2007) e Rojo (2012), Bolognese (2009), Villarreal (2011), entre otros.

Palabras clave: literatura; violencia; política; vanguardia; canon

\section{Memories of violence in Roberto Bolaño's “Amulet”}

Abstract: This essay aims to present an analysis of the violence present in the book "Amuleto" by the Chilean writer Roberto Bolaño. The novel portrays the early 1960s, a time of great political tensions and significant violence in Mexico and the beginning of the Chilean military-business dictatorship (1973-1990). Dictatorial regimes, although in different circumstances, were (and still are) landmark episodes that unite Latin American countries. We will identify the various forms of violence that occurred in Latin America, specifically in Chile and Mexico during the period mentioned, as well as, what is the relationship between politics and literature present in that work. The current political discourses circulating in our society indicate that a large part of the Brazilian population probably ignores a significant part of history, including Brazil, in the 1960s / 1970s, that is the memory produced about this period failed to make known the horrors and the atrocities committed during the more than 20 years of military rule in the country. Based on the approach of the place of poetry and poets in the 1970s, Amuleto's narrator talks about her role as a defender of poetry and the political memory of Mexico and Chile of the mid-20th century, inseparable. With his circular speech, based on the reiteration of traumatic events that witnessed, in particular, the invasion of UNAM, the Tlatelolco Massacre (1968) and the Chilean military coup (1973). In this last fact, reported by the character Arturo Belano, there is a work of memorialistic excavation, both in the historical events mentioned, as well as the poetic intentions of the Mexican federal district. The young poets narrated by the protagonist defended the free transit between life and poetry, opposed the current academic patterns embodied in the figure of Octavio Paz, as well as hegemonic power. The poetic movement of these young Latin Americans in the 1970s adds to the many concerns of their members. The passion for poetry is the basic principle that gives unity to the group that sought in each act and in each verse a 
new way of explaining the world through poetry without bureaucracy, without spaces of power and standardized legitimations. This study contributes to the indispensability of keeping alive the horrors and traumas that happened during the authoritarian regimes and the military dictatorships in Latin America and its reverberations, considering, above all, that memory can be a powerful instrument used in the reconstruction of history. Theoretical and critical texts by Paul Ricoeur (1996), Nascimento (2008), Seligmann-Silva (2003), Sarlo (2007), Rojo (2012), Bolognese (2009), Villarreal (2011), among others, will be used.

Keywords: literature; violence; politics; vanguard; canon.

\section{Memórias da violência em "Amuleto" de Roberto Bolaño}

$O$ que se pretende analisar neste ensaio é como o autor chileno se utiliza das memórias da personagem narradora da obra aqui analisada, Amuleto (1999), Auxilio Lacouture, para questionar o discurso oficial $e$ romper com lugares preestabelecidos, tanto no campo literário como no discurso oficial da história. Este estudo foi desenvolvido a partir das pesquisas e leituras realizadas no decorrer do Curso de Mestrado em Letras, do Programa de Pós-Graduação em Literatura e Cultura, inserido na linha de pesquisa Documentos da Memória Cultural.

O escritor chileno Roberto Bolaño começou sua carreira escrevendo poesia. Seus primeiros textos já indicavam uma ruptura das convenções literárias vigentes. $\mathrm{Na}$ década de 1970, fundou com outros poetas da sua geração 0
Infrarrealismo, movimento literário vanguardista tardio, que buscava na renovação uma nova relação perante a vida, a poesia e as convenções sociais. Uma forte característica do movimento era a oposição aos moldes acadêmicos vigentes, simbolizados, entre outros signos, na figura do poeta mexicano Octavio Paz. De acordo com Chiara Bolognese (2009, p. 131) “[...] es precisamente para oponerse a Paz por lo que los creadores pretendían producir una nueva literatura $y$ distinta ${ }^{3 "}$. E ao poder hegemônico, representado pelo Partido Revolucionário Institucional (PRI), que governou o México entre os anos de 1929 a 2000.

Bolaño (1977, p. 41) afirma e reafirma seu objetivo de enfrentar toda

\footnotetext{
${ }^{3}$ BOLOGNESE (2009, p 131). Tradução nossa: "[...] é precisamente para se opor a Paz que os criadores pretendiam produzir uma literatura nova e totalmente distinta".
} 
e qualquer tentativa de elitização da literatura ao escrever: "[...] la poesía practicada por los vanguardistas de los años veinte fue el primer cartucho disparado contra la literatura canónica imperante y que recién su generación ha disparado el segundo"”. O autor chileno e o movimento Infrarrealismo criticavam a relação dos escritores do boom com o poder. Edmundo Paz Soldán (2013, p. 15) esclarece que nos textos do autor chileno encontramos: "[...] las perversas relaciones que existen en América Latina entre el poder y la letra. Nuestros intelectuales han terminado más una vez seducidos por el poder" Em um dos inúmeros documentários sobre a obra e vida de Bolaño, "Semana do autor, Roberto Bolaño entorno $y$ retorno ${ }^{6 ",}$ o poeta e professor mexicano Rubén Medina afirmou que: "[...] el Infrarrealismo planteó una ética de escribir, una

\footnotetext{
${ }^{4}$ BOLAÑO (1977, p. 41). Tradução nossa: "[...] a poesia praticada pelos vanguardistas dos anos vente foi o primeiro cartucho disparado contra a literatura canônica imperante e que recém sua geração disparou o segundo".

${ }^{5}$ PAZ SOLDÁN (2008, p. 15). Tradução nossa: "[...] as perversas relações que existem na América Latina entre o poder e a letra. Nossos intelectuais terminaram mais uma vez seduzidos pelo poder".

${ }^{6}$ Disponível em: https://www.youtube.com/watch?v=NuS7Oml4FE. Acesso: 28 nov. 2019.
}

posición frente a la literatura, frente a las instituciones","

Portanto, a literatura de Bolaño se caracterizou por criticar, sistematicamente, o academicismo perpetrado pelo discurso oficial, o qual determinava, e ainda determina, em grande parte, quais escritores deveriam e devem ser considerados canônicos. Ainda mais, se pensarmos que um escritor pode ser cânone em seu país e desconhecido em outros lugares. Assim sendo, Bolaño e o movimento Infrarrealismo preconizavam que fosse dada a oportunidade a todos os escritores e não apenas aos que se submetessem às regras do sistema.

Nos últimos 10 anos de vida, já doente, Bolaño se dedicou à narrativa e em muitas de suas obras, como em Amuleto, aqui analisada, o Infrarrealismo está ficcionalizado. A personagem narradora conta uma história que é ao mesmo tempo a sua história e a de muitos outros personagens. Conta também a trajetória de um país que sofreu as ações de um governo quase ditatorial,

\footnotetext{
${ }^{7}$ RUBÉN MEDINA. Disponível em: $<$ https://www.youtube.com/watch?v=NuS7Oml4FE>. Acesso em: 28 nov 2019. Tradução minha: "[...] levantou uma ética de escrever, uma posição frente a literatura, frente as instituições".
} 
- México, relacionando o que para o autor é inseparável: literatura e vida. Bolognese (2009, pp. 34-35) explica que: "El mundo de Bolaño, es un universo donde la literatura y la existencia cotidiana se mezclan continuamente 8 ". Em Amuleto, a narradora afirma: "Yo he vivido las aventuras de la poesía, que siempre son aventuras de vida o muerte" (BOLAÑO, 1999, p. 34).

De acordo com Andrea Carral (2005, p. 4) "[...] el infrarrealismo está llamado a ser 'el ojo de la transición', el testigo que puede dar cuenta de las nuevas experiencias histórico-políticas de la América Latina de mediados de los $70^{9, " . ~ O ~ t e x t o ~ d e ~ a u t o r i a ~ d o ~ t a m b e ́ m ~}$ fundador do Infrarrealismo, Ramón Estrada Rebeldes con causa publicado no manifesto Nada utópico nos es ajeno $^{10}$ (2013, p. 19) afirma que a voz de Bolaño: "[...] abre paso en la selva de textos insulsos y aburridos que saturan el panorama editorial de las

\footnotetext{
${ }^{8}$ BOLOGNESE (2009, pp. 34-35). Tradução nossa: "O mundo de Bolaño é um universo onde a literatura e a existência cotidiana se misturam continuamente".

${ }^{9}$ CARRAL (2005, p. 4). Tradução nossa: "O Infrarrealismo está chamado a ser 'o olho da transição', a testemunha que pode dar conta das novas experiências histórico-políticas da América Latina em meados dos 70".

${ }^{10}$ ESTRADA (2013). Tradução nossa: "Nada utópico nos é distante".
}

instituciones oficiales, y la profecía gana terreno en la geografía de la práctica ${ }^{11 "}$. Assim, é importante ressaltar que a literatura de Roberto Bolaño não aceita os estereótipos deixados pelo realismo mágico, pelo contrário, ela é avessa a esse processo. Em seus textos e em diversas entrevistas, o autor chileno ironiza e critica os escritores latinoamericanos que insistiam em perpetuar o legado do boom, o que retrata, em grande medida, seu posicionamento político e estético.

É neste sentido que surge o Infrarrealismo, movimento político, poético e estético: seu propósito é atacar a cultura oficial, que naquele período estava sob duas correntes, a dos que obtinham a proteção do Estado priista e a representada pelos intelectuais Octávio Paz, Carlos Monsiváis e seus apadrinhados. A proposta do Infrarrealismo, abraçada pelo jovens poetas integrantes do movimento e seduzidos pelos ideais defendidos por Che Guevara, era combater este modelo de cultura perverso, porque ele excluía tudo que

\footnotetext{
${ }^{11}$ ESTRADA (2013, p. 19). Tradução nossa: "[...] abre passo na selva de textos insossos e chatos que saturam o panorama editorial das instituições oficiais, e a profecia ganha terreno na geografia da prática".
} 
não estivesse relacionado ao $\mathrm{PRI} e$ aos seus asseclas. (VILLARREAL, 2011). Conforme explica Caro (2010, p. 77):

Los infrarrealistas se sentían parte de una tradición poética distinta a la convencional. El solo hecho de apartarse de los grandes íconos culturales que eran Paz y Monsiváis, significaba ir por un camino arduo: el del exilio en la propia tierra. Existían dos pilares en la construcción de su identidad, uno era la lucha social, el estar contra el gobierno del PRI y con la revolución - mejor dicho, con la contrarrevolución, con el fin de la aparente igualdad y libertad con las que las autoridades se llenaban la boca - y el otro gran cimiento del movimiento era la pasión por la poesía, la fusión entre vida y arte. Por eso los infra encontraron refugio en José Revueltas y Efraín Huerta ${ }^{12}$..

Na obra em análise, ao dar a uma mulher, Auxilio Lacouture: “[...] ciudadana del Uruguay, latinoamericana, poeta y viajera $^{13,}$ (BOLAÑO, 1999, p. 11), o status de

\footnotetext{
${ }^{12}$ CARO (2010, p. 77). Tradução nossa: "Os Infrarrealistas se sentiam parte de uma tradição poética distinta da convencional. Apenas o fato de se distanciar dos grandes ícones culturais que eram Paz e Monsiváis, significava ir por um caminho árduo: o do exilio na própria terra. Existiam dois pilares na construção de sua identidade, um era a luta social, o estar contra o governo do PRI e com a revolução - melhor dizendo, com a contrarrevolução, com o fim da aparente igualdade e liberdade com as que as autoridades enchiam a boca - e o outro grande cimento do movimento era a paixão pela poesia, a fusão entre vida e arte. Por isso os infra encontraram refúgio em José Revueltas e Efraín Huerta".

${ }^{13}$ BOLAÑO (1999, p. 11). Tradução nossa: "[...] cidadã do Uruguai, latino-americana, poeta e viajante".
}

mãe da poesia e de todos os poetas, Bolaño levanta uma questão relevante no que diz respeito ao modelo normativo. Primeiro, porque a protagonista da obra é uma mulher, o que por si só já seria suficiente para questionar um espaço que foi $e$ continua, predominantemente, masculino, embora, hoje perceba-se uma mudança neste cenário. Segundo, por ser uma mulher latinoamericana. Sobre esse último ponto, cabe lembrar que a literatura de língua hispano-americana passou a ter maior visibilidade após a década de 1960 com o fenômeno do "boom latinoamericano", tendo como principais nomes Gabriel Garcia Márquez, Julio Cortázar, Carlos Fuentes, Mario Vargas Llosa, Juan Carlos Onetti, Alejo Carpentier, Miguel Ángel Asturias, José Donoso, Elena Garrô, Laura Restrepo, Cristina Peri Rossi, entre outros. Aqui importa destacar que mesmo tendo participado, os nomes das escritoras deste período quase nunca são lembrados.

Ressalta-se que os textos de Bolaño atuam no intento de se distanciar dos autores citados como canônicos ou hegemônicos. Para Bolognese (2009, p. 42) "Bolaño [...] 
tomó un posición firme sobre el tema de la herencia de los narrados del boom", [...] se negaba a doblarse a las leyes del mundo del mercado editorial $^{14 " .}$. Em Amuleto, a vida de Auxilio nada tinha de convencional, pois em seu relato ela afirma: "Yo por el día vivía en la Facultad, como una hormiguita o más propiamente como una cigarra, de un lado para otro, de un cubículo a otro cubículo ${ }^{15}[\ldots]$ ". (BOLAÑO, 1999, p.7).

Auxilio é uma figura que, além de não se encaixar no chamado padrão, não tem legitimidade para o discurso oficial. Portanto, Bolaño já inicia a narrativa quebrando paradigmas ao escolher uma mulher como narradora e protagonista de uma história que expõe as discriminações de gênero, sociais e literárias.

A narradora de Amuleto se apresenta como poeta e se auto intitula: "[...] la madre de la poesía

\footnotetext{
${ }^{14}$ BOLOGNESE (2009, p. 42). Tradução nossa: "Bolaño [...] tomou uma posição firme sobre o tema da herança dos narrados do boom", [...] se negava a dobrar-se as leis do mundo do mercado editorial".

${ }^{15}$ BOLAÑO (1999, p. 7). Tradução nossa: "Eu de dia viva na Faculdade, como uma formiguinha ou mais propriamente como uma cigarra, de um lado para outro, de um cubículo a outro cubículo [...]".
}

mexicana $^{16 " .}$ (BOLAÑO, 1999, p.2). Auxilio com suas vivências se percebe como a "mãe" de todos os poetas mexicanos, ou seja, este é o entendimento que ela tem de si mesma e a orientação que dá à sua vida: "Yo soy la madre de los poetas de México ${ }^{17 " .}$. (BOLAÑO, 1999, p.57). Bolaño se apropria das memórias da narradora para produzir o que o autor chama de poesia latino-americana. Essa memória que, a princípio, pode parecer localizada ou puramente pessoal, se coletiviza como uma memória pertencente a uma geração de latino-americanos poetas. Conforme Paul Ricoeur (1996, p. 9) "[...] a memória é sempre a memória de alguém (ou de um grupo) que faz projetos e visa o futuro, pois a memória é o instrumento que traz este passado ao presente, permitindo a construção de novos discursos e saberes".

É a invasão à Universidade Autônoma do México (UNAM) que desencadeia 0 fluxo narrativo de Amuleto, este episódio atormenta a narradora. São reiteradas e frequentes

\footnotetext{
${ }^{16}$ BOLAÑO (1999, p. 2). Tradução nossa: “[...] a mãe da poesia mexicana".

${ }^{17}$ BOLAÑO (1999, p. 57). Tradução nossa: "Eu sou a mãe dos poetas de México".
} 
as lembranças do período em que

ficou presa no banheiro da universidade enquanto alunos, professores e funcionários eram agredidos e presos pela polícia: "Cosa más increíble. Yo estaba en el baño, en los lavabos de una de las plantas de la Facultad, la cuarta, [...]. Y estaba sentada en el water, en el momento en que los granaderos [...] entraban en la Universidad $^{18 " .}$ (BOLAÑO, 1999, p.9).

Auxilio é reclusa deste espaço que reconstituirá sua memória individual sobre este traumático evento.

Ainda que possa parecer linear, a narrativa apresentada por Auxilio é entrecortada pelas recordações dos eventos na UNAM e Tlatelolco ${ }^{19}$.

\footnotetext{
${ }^{18}$ BOLAÑO (1999, p. 12). Tradução nossa: "Coisa mais incrível. Eu estava no banheiro, nos lavabos de uma das plantas da Faculdade, a quarta, [...] E estava sentada no vaso, no momento em que os granadeiros [...] entraram na Universidade".

${ }^{19}$ COSTA (2015, p. 56). O Massacre de Tlatelolco, ocorrido em 1968, foi um ataque militar direcionado ao movimento estudantil em protesto contra os jogos olímpicos. É reconhecido como um evento marcado pela repressão aos estudantes com desproporcionalidade da ação violenta e de seu subsequente encobrimento pelas forças oficiais. Costa afirma que: "O governo, à época, divulgou somente 20 mortes; no entanto, este número é confrontado por historiadores que chegam a afirmar que houve mais de 250 mortos e outras centenas de presos. Com uso de ostensiva força militar e de agentes infiltrados, o exército disparou contra os milhares de manifestantes reunidos na Plaza de las tres Culturas de Tlatelolco. Testemunhas afirmam o uso de estratégias de
}

Como nos alerta Seligmann-Silva (2003, p. 76) "[...] toda escritura do passado [...] é uma (re)inscrição penosa e nunca total". É neste processo de dor e de inúmeros retornos ao passado que a narradora de Amuleto nos dá a conhecer, através de sua memória desconexa carregada de titubeios e sofrimento, que esta será uma história de terror: "Y pensé: así es la Historia, un cuento corto de terror $^{20 " . ~(B O L A N ̃ O, ~ 1999, ~ p .23) . ~}$

O relato de Auxilio é fragmentado, não linear, suas recordações emergem em qualquer ocasião e lugar, indícios de que a memória não pode ser controlada, dada a impossibilidade da tradução total deste passado: "[...] como si el tiempo se fracturara y corriera en varias direcciones a la vez, un tiempo puro, ni verbal ni compuesto de gestos o acciones $^{21}$ [...]". (BOLAÑO, 1999, p. 9). Resgatamos Seligmann-Silva (2003, p. 62), pois para o estudioso:

ágil remoção dos corpos e aprisionamento de manifestantes, de forma a ocultar rapidamente a violência estatal contra a manifestação.

${ }^{20}$ BOLAÑO (1999, p. 23). Tradução nossa: "E pensei: assim é a História, um conto curto de terror".

${ }^{21}$ BOLAÑO (1999, p. 9). Tradução nossa: “[...] como se o tempo se cortasse e corresse em várias direções a vez, um tempo puro, nem verbal nem composto de gestos ou ações [...]". 
"[...] o registro da memória é [...] seletivo e opera no double bind entre lembrança e esquecimento, no tecer e destecer". E de acordo com Beatriz Sarlo (2007, p. 9):

Del pasado no se prescinde por el ejercicio de la decisión ni de la inteligencia; tampoco se lo convoca simplemente por un acto de la voluntad. El regreso del pasarlo no es siempre un momento liberador del recuerdo, sino un advenimiento, una captura del presente ${ }^{22}$.

Tais fatos são recordados pela personagem num discurso interrompido pelas lembranças do passado, impressões do presente e esboço do futuro: "Quiero decir: me puse a pensar en mi pasado como si pensara en mi presente y en mi futuro y en mi pasado, todo revuelto"23. (BOLAÑO, 1999, p.29). Auxilio narra suas memórias rompendo com uma lógica espacial e temporal: "Y mis recuerdos que se remontan sin orden ni concierto hacia atrás y hacia adelante de aquel desamparado mes

\footnotetext{
${ }^{22}$ SARLO (2007, p. 9). Tradução nossa: "Não se prescinde do passado pelo exercício da decisão ou inteligência; tampouco ele é convocado simplesmente por um ato da vontade. O retorno do passado nem sempre é um momento libertador da lembrança, mas um advento, uma captura do presente".

${ }^{23}$ BOLAÑO (1999, p. 29). Tradução nossa: "Quero dizer: me coloquei a pensar em meu passado como se pensasse em meu presente e em meu futuro e em meu passado, tudo revirado".
}

de septiembre de 1968 $24 "$. (BOLAÑO, 1999, p.38).

A memória sobre os episódios mexicanos faz com que Auxilio retorne em muitos momentos da sua narração e, de diversas maneiras, ao dia 18 de setembro de 1968, mais especificamente ao banheiro da Faculdade de Filosofia e Letras da UNAM: "Yo estaba en la Facultad aquel 18 de septiembre cuando el ejército violó la autonomía y entró en el campus a detener o a matar a todo el mundo ${ }^{25 "}$. (BOLAÑO, 1999, p. 9). As memórias da narradora nos levam a um passado marcado pelas atrocidades experienciadas que marcaram a história recente do México: "Y ahora estaba allí, [...] me dije aquí pasa algo raro, Auxilio, nena, abre los ojos y fíjate en los detalles, no sea que se te pase por alto lo más importante de esta historia ${ }^{26 " .}$ (BOLAÑO, 1999, p.16).

\footnotetext{
${ }^{24}$ BOLAÑO (1999, p. 38). Tradução nossa: "E minhas recordações que se referem sem ordem nem gala para atrás e para frente daquele desamparado mês de setembro de 1968 ".

${ }^{25}$ BOLAÑO (1999, p. 9). Tradução nossa: "Eu estava na Faculdade aquele 18 de setembro quando o exército violou a autonomia e entrou no campus a prender ou a matar a todo mundo".

${ }^{26}$ BOLAÑO (1999, p. 16). Tradução nossa: "E agora eu estava ali, [...] e pensei aqui passa algo estranho, Auxilio, criatura, abre os olhos e
} 
MENEZES, Norma Sueli de A.; COSTA, Júlia Morena S. da. Memórias da violência em "Amuleto" de Roberto Bolaño. PragMATIZES - Revista Latino-Americana de Estudos em Cultura, Niterói/RJ, Ano 10, n. 18, p. 278-295, out. 2019 a março 2020.

As delirantes memórias da narradora também fazem alusão a outro acontecimento significativo da história latino-americana, o golpe de Estado chileno. Em Amuleto, este evento, é vivenciado pelo personagem Arturo Belano, que assim como o próprio autor Bolaño, na obra aqui analisada viajou do México ao seu país natal, Chile, para participar do novo momento político após a eleição de Salvador Allende: "[...] el joven Arturo Belano, al que yo conocí cuando tenía dieciséis o diecisiete años, en el año de 1970, [...] que se sentía orgulloso de que en su lejano Chile hubiera ganado las elecciones Salvador Allende" ${ }^{27}$. (BOLAÑO, 1999, p.13).

Dessa maneira, são as recordações da narradora que nos fazem lembrar das adversidades pela qual a América Latina passou (e ainda passa) relacionadas, principalmente, ao que aconteceu quando esteve presa no banheiro da UNAM.

fixe-se nos detalhes, não seja que te passe despercebido o mais importante de esta história".

${ }^{27}$ BOLAÑO (1999, p. 13). Tradução nossa: "[...] o jovem Arturo Belano, que eu conheci quando tinha dezesseis ou dezessete anos, no ano de 1970, [...] que se sentia orgulhoso de que em seu longe Chile houvesse ganhado as eleições Salvador Allende".

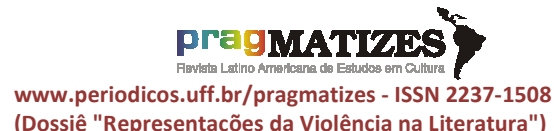

(Dossiê "Representações da Violência na Literatura")

[...] yo me movía feliz de la vida, con todos los poetas de México y con Arturito Belano que tenía diecisiete años, dieciocho años, y que iba creciendo mientras yo lo miraba. ¡Todos iban creciendo amparados por mi mirada! Es decir: todos iban creciendo en la intemperie mexicana, en la intemperie latinoamericana, que es la intemperie más grande porque es la más escindida y la más desesperada [...]. Y yo estaba allí con ellos porque yo tampoco tenía nada, excepto mi memoria. Yo tenía recuerdos. Yo vivía encerrada en el lavabo de mujeres de la Facultad, vivía empotrada en el mes de septiembre del año $1968^{28} \quad$ [...]. (BOLAÑO, 1999, p. 15).

Em Amuleto, Bolaño escolhe eventos históricos importantes da América Latina para construir a narrativa. Ademais, são inúmeras as referências à poesia e aos poetas mexicanos, inclusive, como já mencionado, a própria narradora se autodenomina mãe da poesia e dos poetas mexicanos:

Yo soy la amiga de todos los mexicanos. Podría decir: soy la madre de la poesía mexicana, pero mejor no lo digo. Yo conozco a todos los poetas y todos los poetas me

${ }^{28}$ BOLAÑO (1999, p. 15). Tradução nossa: "[...] eu me movia feliz da vida, com todos os poetas de México y com Arturito Belano que tinha dezessete anos, dezoito anos, e ia crescendo enquanto eu cuidava dele. Todos iam crescendo amparados por meu cuidado! Quer dizer: todos iam crescendo na intempérie latino-americana que é maior porque é a mais dividida e desesperada [...]. Eu tinha recordações. Eu vivia aprisionada no banheiro de mulheres da Faculdade, vivia incrustada no mês de setembro de ano 1968 [...]". 
conocen a mí. Así que podría decirlo $^{29}$. (BOLAÑO, 1999, p. 2).

Neste estudo, defendemos a hipótese de que a personagem narradora Auxilio Lacouture é guardiã da memória histórica do México e do Chile das décadas de 1960-1970. Ao longo da narrativa, as recordações de Auxilio a levam diversas vezes e de muitos modos ao que ocorreu no México em 1968, ou seja, a invasão à Universidade Autônoma do México: "Eso pensaba yo encerrada en el lavabo de mujeres de la cuarta planta de la Facultad de Filosofía y Letras ${ }^{30 ",}$ (BOLAÑO, 1999, p.18), e ao Massacre de Tlatelolco, ambos em setembro de 1968: "En la Universidad no hubo muchos muertos. Fue en Tlatelolco ${ }^{31 ",}$ (BOLAÑO, 1999, p.9), como também ao Chile em 1973, período do golpe de Estado, o que faz com que não nos esqueçamos o que ocorreu nos referidos acontecimentos. Reiteramos

\footnotetext{
${ }^{29}$ BOLAÑO (1999, p. 2). Tradução nossa: "Eu sou a amiga de todos os mexicanos. Podia dizer: sou a mãe da poesia mexicana, porém melhor não o digo. Eu conheço a todos os poetas e todos os poetas me conhecem. Assim que podia lhe dizer".

${ }^{30}$ BOLAÑO (1999, p. 18). Tradução nossa: "Isso eu pensava presa no lavabo de mulheres da quarta planta da Faculdade de Filosofia e Letras".

${ }^{31}$ BOLAÑO (1999, p. 9). Tradução nossa: "Na Universidade não houve muitos mortos. Foi em Tlatelolco".
}

que Auxilio é também guardiã da memória literária latino-americana, porque Bolaño através de sua narradora questiona a literatura, pondo em xeque o fazer poético e os interesses que o circundam. Este pressuposto se evidencia no decorrer do relato da personagem, quando ao longo da narrativa faz menção à literatura chamada cânone ou a produzida pelos jovens poetas marginalizados da cidade do DF, ou seja, é através da poesia que a narradora encontra forças para resistir.

Así que me senté sobre las baldosas del baño de mujeres y aproveché los últimos rayos de luz para leer tres poemas más de Pedro Garfias y luego cerré el libro y cerré los ojos y me dije: Auxilio Lacouture, ciudadana del Uruguay, latinoamericana, poeta y viajera, resiste ${ }^{32}$. (BOLAÑO, 1999, p. 11).

Em Amuleto, o autor chileno contesta o cânone através das memórias da narradora. E o faz passeando pela literatura mundial, de Ovidio, Proust, Celan, Pasolini, Woolf, Borges, Bretón, Huidobro, Cardenal a Paz, entre outros, o que demonstra seu profundo conhecimento da poesia

\footnotetext{
32 BOLAÑO (1999, p. 11). Tradução nossa: "Assim que eu sentei sobre os azulejos do banheiro feminino e aproveitei os últimos raios de luz para ler mais três poemas de Pedro Garfias e logo fechei os olhos e fechei o livro e disse: Auxilio Lacouture, cidadã do Uruguai, latino-americana, poeta y viajante, resiste".
} 
e da narrativa mundial. Cabe destacar que ao mesmo tempo em que dialoga com autores consagrados, Bolaño critica determinados modelos convencionais.

¿Y la buena cultura burguesa? ¿Y la academia y los incendiarios? ¿y las vanguardias y sus retaguardias? ¿Y ciertas concepciones del amor, ¿Y ciertas concepciones del amor, el buen paisaje, la Colt precisa y multinacional? Como me dijo SaintJust en un sueño que tuve hace tiempo: Hasta las cabezas de los aristócratas nos pueden servir de $\operatorname{armas}^{33}$. (BOLAÑO, 2013, p. 54).

Auxilio faz comentários sobre o futuro dos escritores ditos consagrados, o que sinaliza que Bolaño reconhece, ao mesmo tempo em que põe em dúvida este modelo de literatura. Talvez ao usar a palavra "estátua" como metáfora para simbolizar a aura dos escritores, o autor esteja problematizando este reconhecimento, já que para ele, assim como a vida, a aura é susceptível ao esquecimento, ao desaparecimento e, consequentemente, à morte como relata a narradora: "Y lo que los poetas

\footnotetext{
${ }^{33}$ BOLAÑO (2013, p. 54). Tradução nossa: "E a boa cultura burguesa? E a academia e os incendiários? E as vanguardas e suas retaguardas? E certas concepções do amor, a boa paisagem, a Colt precisa e multinacional? Como me disse Saint-Just em um sonho que tive faz tempo: Até as cabeças dos aristocratas podem nos servir de armas".
}

jóvenes o la nueva generación pretendía era mover el piso y llegado el momento destruir esas estatuas, salvo la de Pacheco, el único que parecía escribir de verdad, el único que no parecía funcionario ${ }^{34,}$. (BOLAÑO, 1999, p.20).

Ao trazer para a narrativa escritores dos mais diversos lugares, gêneros e língua Bolaño quebra as barreiras geográficas e discursivas, demonstrando que para Auxilio (e, portanto, para a guardiã da jovem poesia mexicana) uma leitora assídua (como o próprio autor foi), a considerada literatura marginal está no mesmo patamar da considerada cânone. Inclusive, ao longo da narrativa, a personagem faz previsões sobre alguns renomados escritores.

Estoy en el lavabo de mujeres de la Facultad y puedo ver el futuro, decía yo con voz de soprano [...] mis profecías son éstas. Vladímir Maiakovski volverá a estar de moda allá por el año 2150. James Joyce se reencarnará en un niño chino en el año 2124. Thomas Mann se convertirá en un farmacéutico ecuatoriano en el año 2101. Marcel Proust entrará en un desesperado y prolongado olvido a partir del año 2033. Jorge Luis Borges será leído en los túneles en el año 2045. Vicente Huidobro será un poeta de

\footnotetext{
${ }^{34}$ BOLAÑO (1999, p. 20). Tradução nossa: "E o que os poetas jovens ou a nova geração pretendia era mover o piso e chegado o momento destruir essas estatuas, salvo a de Pacheco, o único que parecia escrever de verdade, o único que não parecia funcionário".
} 
masas en el año 2045. Virginia Woolf se reencarnará en una narradora argentina en el año $2076^{35}$. (BOLAÑO, 1999, p. 53).

Desse modo, ao validar 0 cânone, Bolaño não desperdiça as lições do centro, longe disso, faz com que elas sirvam ao seu objetivo, que é literatura, respondendo, afirmativamente, a pergunta de Grinor Rojo (2012, p. 273) ¿Pueden producir los latinoamericanos una literatura propia, original, o están condenados a generar réplicas menores de los grandes modelos metropolitanos ${ }^{36}$ ?

Para Bolaño, valorar alguns poetas em detrimento de outros tantos é fomentar a exclusão, é contribuir para que bons autores que estão à margem continuem apagados. É nesta lógica que sua literatura trabalha,

${ }^{35}$ BOLAÑO (1999, p. 53). Tradução nossa: "Estou no lavabo de mulheres da Faculdade e posso ver o futuro, dizia eu com voz de soprano [...] minhas profecias são estas. Vladímir Maiakovski voltará a estar na moda lá pelo ano 2150. James Joyce se reencarnará em um menino chinês no ano 2124. Thomas Mann se converterá em um farmacêutico equatoriano no ano 2101. Marcel Proust entrará num desesperado e prolongado esquecimento a partir do ano 2033. Jorge Luis Borges será lido nos túneis no ano 2045. Vicente Huidobro será um poeta de massas no ano 2045. Virginia Woolf se reencarnará em uma narradora argentina no ano 2076".

${ }^{36}$ ROJO (2012, p. 273). Tradução nossa: "Podem produzir os latino-americanos uma literatura própria, original, ou estão condenados a gerar réplicas menores dos grandes modelos metropolitanos?" dando luz, trazendo à superfície aqueles que vivem nos: "[...] subterráneos del $\mathrm{DF}^{37}[\ldots]$ ”, na: “[...] red de alcantarillas, [...] en lo más oscuro y en lo más sucio, allí donde el más bragado de los jóvenes poetas no podría hacer otra cosa más que vomitar $^{38 "}$. (BOLAÑO, 1999, p.25). Em Amuleto, a narradora enfrenta 0 discurso oficial ao não fazer distinção entre os textos do chamado cânone e o produzido pelos jovens marginalizados.

[...] una vez me detuve en un pasillo de la Facultad y me uní a un grupo que discutía no sé qué aspectos de la poesía de Ovidio, [...] también estuviera dos o tres poetas jóvenes. [...] machitos que llegaban con sus folios doblados y sus libros sobados y sus cuadernos sucios [...] y me los daban a leer, sus poemas, sus versos, sus ahogadas traducciones, y yo tomaba esos folios y los leía en silencio $^{39}$. (BOLAÑO, 1999, p. 7).

${ }^{37}$ BOLAÑO (1999, p. 25). Tradução nossa: "Subterrâneos do DF".

${ }^{38}$ BOLAÑO (1999, p. 25). Tradução nossa: "[...] rede de esgoto, [...] no mais escuro e no mais sujo, ali onde o mais bravo dos jovens poetas não podia fazer outra coisa mais que vomitar".

${ }^{39}$ BOLAÑO (1999, p. 7). Tradução nossa: “[...] uma vez me detive em um corredor da Faculdade e me uni a um grupo que discutia não sei qual aspectos da poesia de Ovídio [...] também que ali estivesse Monterroso e dois ou três poetas jovens [...] machinhos que chegavam com seus fólios dobrados e seus livros desgastados e seus cadernos sujos e me davam para ler, seus poemas, seus versos, suas afogadas traduções, e eu pegava esses fólios e os lia em silêncio. 
O autor chileno desestabiliza discursos e parâmetros, uma vez que dá ao seu texto novas possibilidades de leitura, confrontando-o com os critérios pré-estabelecidos. O que Bolaño faz é se apropriar das regras impostas pela indústria editorial para questioná-las, como afirmam os escritores Paz Soldán e Faverón (2008, p. 26) "Es imposible enfrentarse a un enemigo poderoso [...], lo mejor, entonces, sería, como estrategia de supervivencia, decir sí y no a la vez: formar parte de la industria cultural, pero tratar de sabotearla desde adentro ${ }^{40}$ ". Esta é uma especificidade da literatura Bolañiana, isto é, sua estética está diretamente associada à forma como o autor se relaciona com o campo literário, ou seja, criticamente. Bolaño trabalha no sentido de romper uma literatura que poderia reafirmar lugares de poder, apostando em literaturas capazes de fazer estabelecer rupturas ou discursos que possam quebrar espaços canônicos preestabelecidos, questionando 0 lugar do ficcional e do discurso oficial.

\footnotetext{
${ }^{40}$ SOLDÁN e FAVERÓN (2008, p. 26).
}

Tradução nossa: "É impossível enfrentar a um inimigo poderoso [...], o melhor, então, seria, como estratégia de sobrevivência, dizer sim e não ao mesmo tempo: formar parte da indústria cultural, mas tratar de sabotá-la de dentro".
As memórias da narradora de Amuleto são escombros, fragmentos de um passado doloroso que é (re)inscrito através dos traços deixados a cada nova lembrança, a cada nova rememoração. Sem distinção de valor, as insistentes recordações de Auxilio recolhem os cacos do passado, como nos assinala Benjamin, para contar uma história inconclusa, sinalizando um passado que não passa, como um fantasma que ronda o presente, ameaçando o retorno das violências e horrores perpetrados por regimes de governo autoritários. Auxilio Lacouture guarda a memória de uma história de terror que deve ser conhecida para que não seja repetida. Portanto, a obra Amuleto colabora para que não esqueçamos de lembrar toda violência produzida pelos regimes autoritários pelos quais passaram muitos países latinoamericanos. Como afirma Sarlo (2007, p. 20) "A memória se torna um dever [...] após o fim da ditadura militar e na maioria dos países da América Latina".

Nesta perspectiva, em Amuleto, a personagem narradora recolhe as imagens rememoradas para tecer uma história que também é sua. Assim, além de reverberar vozes que foram 
MENEZES, Norma Sueli de A.; COSTA, Júlia Morena S. da. Memórias da violência em "Amuleto" de Roberto Bolaño. PragMATIZES - Revista

Latino-Americana de Estudos em Cultura, Niterói/RJ, Ano 10, n. 18, p. 278-295, out. 2019 a março 2020.

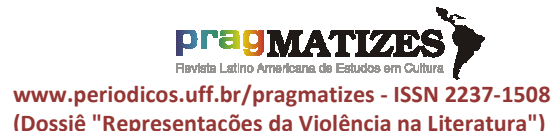

(Dossiê "Representações da Violência na Literatura") silenciadas, as memórias da personagem recuperam o passado e permitem que o que estava oculto possa ser (re)contado e, dessa forma, (re)construído. Sarlo ${ }^{41}$ (2007) nos adverte que: "os protagonistas do passado nem sempre são os que falam, pois muitas vezes estão mortos". Portanto, percebemos que Auxilio Lacouture se configura como a guardiã das memórias históricas e literárias, porque é através das suas rememorações que a voz daqueles que foram apagados (estudantes, jovens e poetas) reverberam e operam para nos fazer lembrar o que houve no México e no Chile nas décadas de 1960-1970.

Ao retomar histórias recentes da América Latina que foram apagadas pela história oficial, Bolaño nos apresenta a maneira como esta foi constituída, expõe o que nela ficou escondido e revela a precariedade da vida daqueles que estão à margem, na periferia. De acordo com Judith Butler (2016) aqueles que estão fora dos quadros normativos, como é o caso de

\footnotetext{
${ }^{41}$ O Estado de S. Paulo 03/04/2007 na edição 427. Entrevista Beatriz Sarlo. O terror e a memória num beco sem saída. Disponível em:http://observatoriodaimprensa.com.br/inter esse-publico/o-estado-de-s-paulo-33438/. Acesso: 05 jul. 2019.
}

Auxilio e dos jovens poetas, sequer alcançam o reconhecimento, não têm direito a vidas vivíveis nem passíveis de luto.

$\mathrm{Na}$ verdade, uma figura viva fora das normas da vida não somente se torna o problema com o qual a normatividade tem que lidar, mas parece ser aquilo que a normatividade está fadada a reproduzir: está vivo, mas não é uma vida. Situa-se fora do enquadramento fornecido pela norma, mas não apenas como um duplo implacável cuja ontologia não pode ser assegurada, mas cujo estatuto de ser vivo está aberto à apreensão. (BUTLER, 2016, p. 22).

É recuperando a memória através do testemunho da personagem narradora que Bolaño nos possibilita reinterpretar a história, porque é a partir dos traumas gravados nas memórias delirantes da narradora Auxilio que se dá a conhecer o que foi ocultado pela história.

[...] los soldados y los granaderos estaban deteniendo y cacheando y pegándole a todo el que encontraban delante sin que importara sexo 0 edad, condición civil 0 status adquirido (o regalado) en el intrincado mundo de las jerarquías universitarias $^{42}$. (BOLAÑO, 1999, p. 9).

\footnotetext{
${ }^{42}$ BOLAÑO (1999, p. 9). Tradução nossa: "[...] os soldados e os granadeiros estavam detendo e cacheando e pegando a tudo o que encontravam diante sem que importara sexo ou idade, condição civil ou status adquirido (o presenteado) no intrincado mundo das hierarquias universitárias".
} 
Assim, mais uma vez, está demonstrado que as memórias da personagem sobre a invasão a UNAM e o Massacre de Tlatelolco cumprem o papel de nos lembrar, todo o tempo, os episódios que marcaram o México naquele setembro de 1968. Para isso, Bolaño se apropria do que Evando Nascimento (2008) chama de rastros, ruínas para dizer 0 indizível, potencializando as micro intervenções que alteram a linguagem, pois propõem outras possibilidades de literatura (real e ficcional). A reconfiguração de algo, o torna ambíguo, nele se situa o entre lugar que reitera ao mesmo tempo sua aura, sua especificidade, recriando-o, produzindo nele uma potência. Segundo Derrida (2014, p. 53) a literatura "[...] é uma arma política muito poderosa". Assim, entendemos que a literatura de Bolaño não é neutra, já que o autor chileno se apropria dela para tomar partido, revelando de que lado ele está.

A literatura para Roberto Bolaño esteve sempre relacionada às questões cotidianas, sociais e políticas. Seus livros aludem bem este posicionamento. Não raro, encontramos em sua obra evidências de que os fatos ali narrados ficcionalizam situações que fizeram parte da sua vida ou de pessoas próximas a ele. São nomes de personagens, fatos históricos e textos que rompem os padrões literários e poéticos, na obra aqui analisada Bolaño nos apresenta Auxilio Lacouture como guardiã da memória histórica e poética do período de 19601970 no México e no Chile. Ao recuperar a história política e literária e artística da América Latina, Bolaño questiona o discurso tradicional, expondo o que ficou oculto pela história oficial. Nesta perspectiva, o autor chileno rompe com os padrões estéticos vigentes ao usar suas próprias experiências como estratégia de intervenção.

A narradora de Amuleto surge tecendo o discurso de uma perspectiva que não a autorizada, de uma ótica sustentada na experiência que até então, deveria, de acordo com os padrões "tradicionais" continuar secundarizada. O lugar de fala da personagem Auxilio é instável, desconfortável, trata-se de um sujeito periférico, excluído que carrega na instabilidade a potência que empodera o coletivo marginalizado. Dessa 
maneira, em Amuleto, Bolaño principia a destruição deste tempo violento e, sobretudo, excludente, para construção de um presente menos desigual.

Destarte, é necessário que o leitor esteja atento às pistas que são apresentadas sob as formas de memórias delirantes da personagem narradora, que aparentemente se manifestam de maneira generalizada, traçam um vínculo entre os fatos por ela relatados e sua vida, esclarecendo aos poucos qual história será contada. Bolaño se utiliza da própria literatura para se expressar politicamente e na crítica literária, traz outras formas de se pensar o campo literário ao fazer uso da sua escrita para questionar e desconstruir 0 pensamento hegemônico que se constituiu dicotomicamente.

Ao trazer em Amuleto uma personagem que carrega em suas memórias inúmeras referências aos fatos históricos, políticos e a escritores consagrados, Bolaño põe em prática o que defende o Infrarrealismo, ou seja, não separar literatura da vida, porque conforme Andrés Braithwaite (2006, p. 25), para o autor chileno "[...] toda escritura, de alguna manera, es un acto social ${ }^{43 "}$. Assim sendo, para 0 autor chileno, não há como separar vida e obra, porque é tudo [...] unasola-cosa $^{44 ” .}$ (BOLAÑO, 2013, p.1), melhor dizendo, "[...] un compromiso, o mejor dicho, una apuesta, en donde el artista pone la mesa su vida ${ }^{45}[\ldots] "$. (BOLAÑO, 2013, p. 3).

Por fim, entendemos que ao recuperar a história política e literária e artística da América Latina, Roberto Bolaño contesta, de dentro do sistema e de inúmeras formas, os espaços de legitimação, utilizando-se dos critérios que ainda hoje determinam o que pode ou não ser considerado cânone. Ademais, defendemos que sua literatura, em especial Amuleto, coloca em dúvida a construção do discurso oficial acerca dos fatos recentes que marcaram 0 continente latinoamericano, especificamente, o México e o Chile.

\section{Referências bibliográficas}

BOLAÑO, Roberto. Amuleto. Barcelona: Editorial Anagrama, 1999.

\footnotetext{
${ }^{43}$ BRAITHWAITE (2006, p. 25). Tradução minha: "[...] toda escritura, de alguma maneira, é um ato social".

${ }^{44}$ BOLAÑO (2013, p. 1). Tradução minha: “[...] uma-só-coisa [...]"

${ }^{45}$ BOLAÑO (2013, p. 3). Tradução minha: "[...] um compromisso, ou melhor dizendo, uma aposta, onde o artista põe sua vida na mesa".
} 
BOLAÑO, Roberto. Déjenlo todo nuevamente. Manifesto Infrarrealista. 2013. Disponível em:www.infrarrealismo. Acesso: $3 \mathrm{dez}$. 2016.

BOLOGNESE, Chiara. Roberto Bolaño y sus comienzos literarios: El infrarrealismo entre realidad y ficción. Acta literária, n. 39, p. 131-140, 2009. Disponível em: http://www.scielo.cl/scielo.php?script=s ci_arttext\&pid=S071768482009000200 010. Acesso: 12 fev. 2019.

BRAITHWAITE, Andrés. Bolaño por sí mismo: entrevistas escogidas. Chile: Ediciones Universidad Diego Portales, 2006.

BUTLER, Judith. Vida Precária, vida passível de luto. In: Quadros de Guerra. Quando a vida é passível de luto? Rio de Janeiro: Civilização Brasileira, 2016. p. 13-55.

CARO, Montserrat Madariaga. Bolaño Infra 1975 - 1977: los años que inspiraron Los detectives salvajes. Santiago: RIL editores, 2010.

CARRAL, Andrea Cobas. Déjenlo todo nuevamente: apuntes sobre el movimiento infrarrealista mexicano. 2005. Disponível em: http://letras.s5.com.istemp.com/rb0511 05.htm. Acesso: 21 maio 2019.

COSTA, Júlia Morena Silva da. Estética do fracasso: o projeto literário de Bolaño. 2015. 232 f. Tese (Doutorado em Literatura e Cultura). Universidade Federal da Bahia, Salvador, 2015.

DERRIDA, Jacques. Essa estranha instituição chamada Literatura: uma entrevista com Jacques Derrida. Belo Horizonte: Editora UFMG, 2014.

ESTRADA, Ramón. Déjenlo todo nuevamente. Manifesto Infrarrealista. 2013. Disponível em: www.infrarrealismo. Acesso: 03 dez. 2019.

MEDINA, Rubén. Documentário sobre a obra e vida de Bolaño. Semana de autor, Roberto Bolaño entorno y retorno. Disponível em: https://www. youtube.com/watch?v=Nu S-7OmI4FE. Acesso: 28 ago. 2019.

NASCIMENTO, Evando. Retrato desnatural (diários - 2004 a 2007). Rio de Janeiro: Record. 2008.

PAZ SOLDÁN, Edmundo; FAVERÓN Patriau, G. Bolaño Salvaje. España: Editorial Candaya, 2013.

RICOEUR, Paul. A memória, a história, o esquecimento. Campinas, SP: Editora da Unicamp, 2007.

ROJO, Grínor. De las más altas cumbres. Teoría Crítica latinoamericana moderna. Santiago de Chile: LOM Ediciones, 2012.

SARLO, Beatriz. O terror e a memória num beco sem saída. $O$ Estado de $S$.

Paulo, São Paulo, 01 abr. 2007.

Caderno Cultura. Disponível em:

http://observatoriodaimprensa.com.br/i nteresse-publico/o-estado-de-s-paulo33438/. Acesso: 05 jul. 2019.

SARLO, Beatriz. Tempo passado: cultura da memória e guinada subjetiva. São Paulo: Companhia das Letras, 2007.

SELIGMANN-SILVA, Marcio. Reflexões sobre a memória, a história e o esquecimento. In: Seligmann-Silva, M. (org.). História, Memória, Literatura. O testemunho na era das catástrofes. Campinas, SP: Ed. UNICAMP, 2003.

VILLARREAL, Rogelio. El gran rechazo: underground y contracultura. Revista Replicante, nov. 2011. Disponível em: http://revistareplicante.com/destacados /elgran-rechazo/. Acesso: 02 abr. 2019. 